\title{
Impact of $\mathrm{HNO}_{3}$ Solution Treatment of South Brazil Coal Matrices on Their Chemical Composition and Humic Acids Yield
}

\author{
Deborah P. Dick, *,a Janaina B. da Costa, ${ }^{a}$ Anderson José B. Leite ${ }^{a}$ and \\ Eduardo A. Brocchi ${ }^{b}$ \\ anstituto de Química, Universidade Federal do Rio Grande of Sul (UFRGS), \\ 91501-970 Porto Alegre-RS, Brazil \\ ${ }^{b}$ Departamento de Engenharia Química e de Materiais, \\ Pontifícia Universidade Católica do Rio de Janeiro (PUC-Rio), \\ 22451-900 Rio de Janeiro-RJ, Brazil
}

\begin{abstract}
In this study, changes on the chemical composition and on the humic acids yield of coal matrices promoted by $25 \% \mathrm{HNO}_{3}$ treatment were investigated, by means of elemental, thermogravimetric analyses, and Fourier transform infrared spectroscopy (FTIR). The "run of mine" (ROM) matrix C-MTR (ROM coal) showed the highest $\mathrm{C}$ content (41\%), highest $\mathrm{C} / \mathrm{N}$ ratio (76) and lowest ash content $(54 \%)$ of the studied samples. In contrast, coal tailings presented a higher degree of aromaticity. Treatment with $\mathrm{HNO}_{3}$ solution increased $\mathrm{N}$ content, but not that of $\mathrm{C}$. Therefore, the $\mathrm{C} / \mathrm{N}$ ratio of all samples decreased to values between 11 and 20 . The insertion of $\mathrm{N}$ occurred in the aromatic structures, while the oxidation occurred in both the aromatic and aliphatic chains. $\mathrm{HNO}_{3}$ treatment increased the humic substances content and the largest increase being observed in the coal tailings ( 16 to $31 \%$ increment in comparison to the untreated sample). The generated humic acids showed in general a chemical composition similar to that of soil humic acids, but a greater aromaticity degree.
\end{abstract}

Keywords: humic substances, coal oxidation, FTIR spectroscopy, TGA

\section{Introduction}

Coal deposits in South Brazil represent about $90 \%$ of the national coal resources, but its use as a fuel source or in the metallurgical industry is highly restricted due to its low rank and high ash content. ${ }^{1}$ In Brazil, about $75 \%$ of the mined material is discarded after beneficiation process. The great amount of produced coal tailing is usually stored in open piles and a strong acidification of the surrounding environment is observed due to the formation of acid mine drainage..$^{2,3}$

A sustainable fate for this coal residue is the production of humic substances (HS) that, besides being a source of $\mathrm{C}$ and $\mathrm{N}$ to microorganisms and plants, plays an important role in chemical and physical properties of the soil. ${ }^{4}$ Environmental benefits of HS are mainly related to their high complexing capacity for metal ions that results from the oxygen-containing functional groups present in their structure associated to their high specific surface. ${ }^{5,6}$

*e-mail: debby.dick@gmail.com
The use of oxidative chemical methods for increasing the yield of humic acids (HA) of coal and similar carbonaceous samples is well known and it is widely reported in the scientific literature since $1930 .^{7-10}$ However, systematic studies that investigate the effects of these methods in the chemical composition of both the bulk coal sample and of their HS are less frequent. Usually, spectroscopic and chemical characterization is focused on the coal HA since the purification of this fraction is easily attainable. ${ }^{10-12}$ The difficulty in analyzing the chemical composition of the organic fraction of coal matrices arises from the presence of inorganic components. To overcome the interference of the inorganic matrix in the spectroscopic, thermic, pyrolitic and chemical analyses, the treatment with diluted hydrofluoric acid (HF) solution has been used in soil samples in order to concentrate carbon and remove paramagnetic compounds. ${ }^{13,14}$ According to Rumpel et al., ${ }^{14}$ no major alteration of the chemical composition of soil organic matter, as assessed by ${ }^{13} \mathrm{C}$ nuclear magnetic resonance (NMR) and Fourier transform infrared spectroscopy (FTIR), occurs due to HF treatment. 
Oxidation of carbonaceous matrices employing nitric acid solution with different concentrations ( 5 to $25 \%$ ) has been used with both fossil coal and biochar. ${ }^{11,15}$ Fong et al..$^{11}$ tested three different reagents $\left(\mathrm{HNO}_{3}, \mathrm{H}_{2} \mathrm{O}_{2}\right.$ and $\mathrm{KMnO}_{4}$ ) for the oxidation of low rank coal samples from Indonesia. The obtained HA from the different methods were compared in light of their gravimetric yields and chemical characteristics determined by spectroscopic techniques. The oxidized coal with $10 \% \mathrm{HNO}_{3}$ solution produced a higher HA yield which showed a greater exchangeable acidity (-COOH and $\mathrm{OH}-$ phenolic) when compared to HA from samples treated by other methods. Besides increasing the oxygen-containing groups in the coal structure due to the oxidation of alkyl groups, ${ }^{11}$ it is proposed that the treatment with nitric acid promotes the carboxylic and nitro substitution on the aromatic ring. ${ }^{16}$

Considering the high waste generation from coal mining activity in Southern Brazil, the development of strategies for a sustainable destination for these wastes is interesting from both economic and ecological points of view. The residues remaining after coal beneficiation for energetic purposes may still contain a reasonable amount of organic fraction that is susceptible of oxidation, and thus capable to generate HS. In this context, the main purpose of this work was to evaluate the potential of coal tailing samples from South Brazil to produce HS, after treating the samples with $\mathrm{HNO}_{3}$ solution, and to investigate the resulting chemical composition alterations. Besides the HA yield determination, the chemical composition of four coal samples and of the extracted HA were investigated before and after treatment with $\mathrm{HNO}_{3}$ solution by means of elemental analyses, thermogravimetric and FTIR spectroscopy. Three samples of coal tailings from representative mines from Santa Catarina State were studied and, for comparison purposes, one sample of "run of mine" (ROM) was also included in the study.

\section{Experimental}

\section{Coal matrices}

The studied samples belong to the Paraná Basin, a large sedimentary basin situated in central eastern South America, including parts of Brazil, Argentina, Paraguay and Uruguay. ${ }^{17}$ Four coal matrices were collected in a mining region in Santa Catarina State and consisted of: a ROM coal and its tailing sample (C-MTR and R-MTR, respectively) from the "Bonito" layer in Criciúma County $\left(28^{\circ} 40^{\prime} \mathrm{S}, 49^{\circ} 28^{\prime} \mathrm{W}\right)$; a pyrite-rich coal tailing from the "Barro Branco" layer (R-FOR) (Forquilinha County, $28^{\circ} 44^{\prime} \mathrm{S}, 49^{\circ} 28^{\prime} \mathrm{W}$ ) and a coal tailing sample (RBC) from the "Bonito" layer located in Treviso County $\left(28^{\circ} 30^{\prime} \mathrm{S}\right.$, $49^{\circ} 27^{\prime} \mathrm{W}$ ). All samples were air dried, ground in an agate mortar and dried at $60{ }^{\circ} \mathrm{C}$ for 12 hours.

Treatment with $\mathrm{HNO}_{3}$ solution

Samples were treated with $25 \% \mathrm{HNO}_{3}$ solution according to Trompowsky et al..$^{15}$ The experimental procedure was conducted on a system under reflux of the Soxhlet type. In $500 \mathrm{~mL}$ flask, $2.0 \mathrm{~g}$ sample and $100 \mathrm{~mL}$ of $\mathrm{HNO}_{3}$ solution were added. The system was kept under reflux for 4 hours at a temperature of $60^{\circ} \mathrm{C}$. Next, the flask containing the acid solution was left to stand overnight for cooling and sedimentation of the samples. The supernatant was separated by centrifugation and the acid extract was collected and its volume measured. The solid sample was washed three times with distilled water and transferred to a pre-weighed beaker and dried in an oven at $60{ }^{\circ} \mathrm{C}$. After drying, the sample was cooled in a desiccator. The yield of the nitration was calculated gravimetrically. In order to reduce nitric acid wastes, the same procedure was performed with a $11 \% \mathrm{HNO}_{3}$ solution following the recommendation of Fong et al. ${ }^{11}$ However, the yield using $11 \% \mathrm{HNO}_{3}$ solution was always lower than that obtained with $25 \% \mathrm{HNO}_{3}$ solution and therefore the results obtained with the less concentrated solution will not be presented and discussed.

\section{Sample demineralization with $10 \%$ HF solution}

Prior to thermogravimetric and FTIR analysis, the coal matrices $\left(\mathrm{HNO}_{3}\right.$ untreated and $\mathrm{HNO}_{3}$ treated) were demineralized with $10 \% \mathrm{HF}$ solution to remove the inorganic components and concentrate the organic matter. ${ }^{13}$ Using a plastic container, coal matrices $(10 \mathrm{~g})$ were treated with $30 \mathrm{~mL}$ of a $10 \%(\mathrm{~m} / \mathrm{m}) \mathrm{HF}$ solution. After $2 \mathrm{~h}$ of mechanical agitation with subsequent centrifugation $(1529 \times \mathrm{g}, 10 \mathrm{~min})$, the supernatant was removed and discarded. This procedure was repeated six times. The remaining sample was washed five times with deionized water and dried at $60{ }^{\circ} \mathrm{C}$ in a vacuum oven.

Elemental analysis, infrared spectroscopy, and thermogravimetric analysis

The elemental composition $(\mathrm{C}, \mathrm{H}, \mathrm{N})$ of the bulk and of the $\mathrm{HF}$ treated coal matrices $\left(\mathrm{HNO}_{3}\right.$ untreated and $\mathrm{HNO}_{3}$ treated) was determined by dry combustion $\left(975{ }^{\circ} \mathrm{C}\right)$ (PerkinElmer 2400 elemental analyzer). The relation $\mathrm{C} / \mathrm{N}$ and the molecular ratio $\mathrm{H} / \mathrm{C}$ were calculated. The ash 
content was determined gravimetrically after heating the sample at $750^{\circ} \mathrm{C}$ for $4 \mathrm{~h}$.

Chemical characterization by elemental analysis was performed on the coal matrices $\left(\mathrm{HNO}_{3}\right.$ untreated and $\mathrm{HNO}_{3}$ treated; bulk and HF treated). Fourier transform infrared spectroscopy analysis (FTIR) was performed on a Shimadzu FTIR 8300 in KBr pellets (1 mg sample: $100 \mathrm{mg} \mathrm{KBr}$ ) employing 32 scans and $4 \mathrm{~cm}^{-1}$ resolution, at a spectra range between 4000 and $400 \mathrm{~cm}^{-1}$. Attribution of absorption bands followed $\operatorname{Tan}^{18}$ and Farmer ${ }^{19}$ and the aromaticity index $\left(\mathrm{I}_{1630} / \mathrm{I}_{2920}\right)^{20}$ was calculated. The relative intensities (RI) of the main absorption bands were calculated according to Gerzabek et al.,${ }^{21}$ by dividing the corrected intensity of a given peak (e.g., approximately $\left.2920,1720,1630,1540,1080 \mathrm{~cm}^{-1}\right)$ by the sum of the intensities of selected bands multiplied by $100 \%$. The limits $\left(\mathrm{cm}^{-1}\right)$ for determining the base line of each band were established as follows: (base1/peak/base2) = 3100/2920/2800; 1800/1720/1700; 1700/1630/1500; $1600 / 1540 / 1490 ; 1200 / 1080 / 900 .{ }^{21}$

Thermogravimetric (TGA) analyses of $10 \% \mathrm{HF}$ treated samples $\left(\mathrm{HNO}_{3}\right.$ untreated and $\mathrm{HNO}_{3}$ treated) were carried out with a thermo-gravimetric analyzer (TGA Q5000IR-TA instruments) using $10 \mathrm{mg}$ of sample. Firstly, the initial weight was stabilized at $45^{\circ} \mathrm{C}$, and the heating curve was obtained with a heating rate of $20^{\circ} \mathrm{C} \mathrm{min}^{-1}$ up to $105^{\circ} \mathrm{C}$ (holding time of $5 \mathrm{~min}$ ), followed by a heating rate of $10{ }^{\circ} \mathrm{C} \mathrm{min}^{-1}$ up to $1000{ }^{\circ} \mathrm{C}^{22}$ Thermo-decomposition curves were divided into five main regions of temperature, whose limits varied among the samples. Two thermogravimetric index (TGI) were calculated from the thermo-decomposition curve (see Results and Discussion section).

\section{Extraction and quantification of humic substances (HS)}

Extraction of $\mathrm{HS}$ was performed in the coal matrices (both $\mathrm{HNO}_{3}$ untreated and $\mathrm{HNO}_{3}$ treated) according to Swift, ${ }^{23}$ and quantified based on Dick et al. ${ }^{24}$ Thirty milliliters of $0.5 \mathrm{~mol} \mathrm{~L}^{-1} \mathrm{NaOH}$ were added to $1 \mathrm{~g}$ of sample, and the suspension was stirred for $3 \mathrm{~h}$. The alkaline extract was separated by centrifugation $(1529 \times \mathrm{g}$, $10 \mathrm{~min}$ ) and stored in a polyethylene flask. This procedure was repeated until the extract became colorless (total of 6 extractions). The final volume of alkaline extract was measured, and an aliquot $(5 \mathrm{~mL})$ was separated for HS quantification. The alkaline solution was acidified to pH 2.0 using $4.0 \mathrm{~mol} \mathrm{~L}^{-1} \mathrm{HCl}$ and, after standing $24 \mathrm{~h}$, it was centrifuged to separate the supernatant FA, from HA (pellet). The final volume of the FA extract was measured. $\mathrm{C}$ concentration in the soluble $\mathrm{HS}\left(\mathrm{C}_{\mathrm{HS}}\right)$ and $\mathrm{FA}\left(\mathrm{C}_{\mathrm{FA}}\right)$ extracts was determined by the absorbance at
$580 \mathrm{~nm}$ (Shimadzu UV-160 A) following oxidation with $\mathrm{K}$ dichromate in an acid medium at $60^{\circ} \mathrm{C}$ for $4 \mathrm{~h}$. The HA concentration $\left(\mathrm{C}_{\mathrm{HA}}\right)$ was calculated as follows:

$\mathrm{C}_{\mathrm{HA}}=\mathrm{C}_{\mathrm{HS}}-\mathrm{C}_{\mathrm{FA}}$

Determination of humic acids yield and chemical composition

HA were extracted from the coal matrices C-MTR, R-MTR, R-FOR and RBC, both $\mathrm{HNO}_{3}$ untreated and nitrated. After separation of the FA, HA were purified with $5 \% / 5 \% \mathrm{HCl} / \mathrm{HF}$ solution for $2 \mathrm{~h}$ under mechanical shaking (three times). ${ }^{24}$ The purified HA were washed three times with distilled water, frozen overnight, and dried at $60{ }^{\circ} \mathrm{C}$ in vacuum oven. The dried samples were maintained in a desiccator with silica gel for further analysis. Purified HA were characterized by elemental analysis and infrared spectroscopy (FTIR).

\section{Results and Discussion}

\section{Elemental composition and ash content of coal matrices}

C-MTR sample, (ROM coal) contained $41 \% \mathrm{C}$ and $0.55 \% \mathrm{~N}$ (Table 1). These results, associated with the high ash content (Table 1), characterize a low rank coal as it was expected for the coal basin of the Santa Catarina State. ${ }^{1}$ The $\mathrm{C}$ content of the three coal tailings varied between 6.8 and $16.2 \%$ and that of $\mathrm{N}$ between 0.16 and $0.29 \%$ (Table 1).

R-MTR sample showed lower levels of $\mathrm{C}$ and $\mathrm{N}$ and higher ash content than its respective ROM coal, C-MTR (Table 1). The beneficiation process of coal separates the fraction with higher calorific power (higher $\mathrm{C}$ content) from that with lower $\mathrm{C}$ content, and therefore these results were expected.

In general, the contents of $\mathrm{N}$ were consistent with those commonly observed in Southern Brazil coals. ${ }^{1} \mathrm{C} / \mathrm{N}$ values varied between 42 and $76 \%$, which is coherent for $\mathrm{N}$-depleted samples. However, the coal tailings presented the lowest $\mathrm{C} / \mathrm{N}$ values and it seems that the beneficiation of coal promotes a relative enrichment in the $\mathrm{N}$-containing structures.

After treatment with $10 \%$ HF solution, all samples showed higher contents of $\mathrm{C}, \mathrm{H}$ and $\mathrm{N}$, indicating that the inorganic components were partially removed and consequently the organic fraction was enriched. The decrease of the ash content after 10\% HF confirmed the solubilization of the mineral fraction (Table 1). For C-MTR $\mathrm{HF}_{\mathrm{HF}}$ and R-MTR $\mathrm{HF}_{\mathrm{HF}}$ samples, ash content decreased to 13 and $18 \%$, respectively, while in the R-FOR $\mathrm{HF}_{\mathrm{HF}}$ and $\mathrm{RBC}_{\mathrm{HF}}$ samples the ash content was still relatively high after treatment with $10 \%$ HF. This different behavior in 
Table 1. Elemental composition, $\mathrm{C} / \mathrm{N}$ ratio and $\mathrm{H} / \mathrm{C}$ atomic ratio of coal matrices C-MTR, R-MTR, R-FOR and RBC before and after treatment with $10 \%$ HF solution

\begin{tabular}{lcccccc}
\hline Sample & $\mathrm{C} / \%$ & $\mathrm{~N} / \%$ & $\mathrm{H} / \%$ & $\mathrm{C} / \mathrm{N}$ & $\mathrm{H} / \mathrm{C}$ & $\mathrm{Ash} / \%$ \\
\hline C-MTR & $41.20 \pm 0.09^{\mathrm{a}}$ & $0.55 \pm 0.08$ & $2.05 \pm 0.37$ & $75 \pm 1.1$ & $0.60 \pm 0.11$ & 54 \\
R-MTR & $16.21 \pm 0.88$ & $0.29 \pm 0.01$ & $1.52 \pm 0.01$ & $56 \pm 0.3$ & $1.12 \pm 0.07$ & 62 \\
R-FOR & $6.75 \pm 0.34$ & $0.16 \pm 0.01$ & $0.78 \pm 0.04$ & $42 \pm 2.1$ & $1.40 \pm 0.07$ & 78 \\
RBC & $11.74 \pm 1.11$ & $0.27 \pm 0.06$ & $1.00 \pm 0.01$ & $43 \pm 0.6$ & $1.02 \pm 0.03$ & 84 \\
C-MTR $_{\mathrm{HF}}$ & $64.48 \pm 7.46$ & $1.19 \pm 0.20$ & $3.72 \pm 0.18$ & $54 \pm 2.8$ & $0.69 \pm 0.05$ & 18 \\
R-MTR $_{\mathrm{HF}}$ & $62.12 \pm 5.36$ & $1.07 \pm 0.08$ & $3.73 \pm 0.23$ & $58 \pm 0.4$ & $0.72 \pm 0.02$ & 13 \\
R-FOR $_{\mathrm{HF}}$ & $25.80 \pm 0.70$ & $0.46 \pm 0.03$ & $1.34 \pm 0.26$ & $56 \pm 0.7$ & $0.62 \pm 0.01$ & 49 \\
RBC $_{\mathrm{HF}}$ & $15.10 \pm 0.40$ & $0.36 \pm 0.20$ & $9.30 \pm 0.30$ & $42 \pm 2.8$ & $0.74 \pm 0.00$ & 46 \\
\hline
\end{tabular}

amean $(\mathrm{n}=2) \pm$ standard deviation; HF: samples demineralized with $10 \%$ HF solution.

the dissolution of the inorganic fraction can be associated to the mineral heterogeneity of the studied samples, which was not investigated in our study.

Infrared spectroscopy of coal matrices before and after treatment with $10 \% \mathrm{HF}$ solution

The most important features of the FTIR spectra of the coal matrices (Figure 1a) are: (i) three bands between $3709-3690 \mathrm{~cm}^{-1}$ due to $\mathrm{O}-\mathrm{H}$ stretching of $\mathrm{Al}-\mathrm{OH}$ and $\mathrm{Si}-\mathrm{OH}$ groups; (ii) a band at $3411 \mathrm{~cm}^{-1}$ due to $\mathrm{O}-\mathrm{H}$ stretching; (iii) a couple of peaks at 2920 and $2845 \mathrm{~cm}^{-1}$ due to aliphatic $\mathrm{C}-\mathrm{H}$ stretching; (iv) a band at $1623 \mathrm{~cm}^{-1}$ attributed to angular deformation of hydration water; $(v)$ a prominent band at $1028 \mathrm{~cm}^{-1}$ attributed to $\mathrm{Si}-\mathrm{O}$ stretching; (vi) a couple of bands at 560 and $472 \mathrm{~cm}^{-1}$ attributed to $\mathrm{Fe}-\mathrm{O}$ stretching of $\mathrm{Fe}_{2} \mathrm{O}_{3}$. For sample C-MTR, which displays the greatest $\mathrm{C}$ content, the bands of the inorganic groups were comparatively less intense than other matrices spectra, in comparison to those of the organic groups (Figure 1a).

After treatment with $10 \%$ HF solution, bands corresponding to the minerals at $3709-3690 \mathrm{~cm}^{-1}$ and $1623 \mathrm{~cm}^{-1}$ decreased, thus enabling the identification of organic functional groups (Figure 1b). In Figure 1b, the main identified bands and their assignments were: a peak at $3416 \mathrm{~cm}^{-1}$ due to $\mathrm{OH}$ groups; bands at $3192-3045 \mathrm{~cm}^{-1}$ attributed to stretching of the aromatic $\mathrm{C}-\mathrm{H}$ groups; bands at $2920-2850 \mathrm{~cm}^{-1}$ due to the $\mathrm{C}-\mathrm{H}$ stretching of aliphatic; band at $1601 \mathrm{~cm}^{-1}$ due to the stretching of $\mathrm{C}=\mathrm{C}$ of aromatics; band at $1440 \mathrm{~cm}^{-1}$ due to $\mathrm{C}-\mathrm{H}$ deformation of aliphatic; peak at $1032 \mathrm{~cm}^{-1}$ assigned to the stretching of the mineral fraction of $\mathrm{Si}-\mathrm{O}$.

C-MTR ${ }_{\mathrm{HF}}$ sample showed higher values for $\mathrm{RI}_{2920}$ and $\mathrm{RI}_{1430}$ and lower ones for $\mathrm{RI}_{3200}$ and $\mathrm{RI}_{1608}$ than R-MTR $\mathrm{HF}_{\mathrm{HF}}$ sample (Table 2), indicating that the ROM coal sample has comparatively higher proportion of aliphatic groups than the respective coal tailing. Enrichment of aromatic

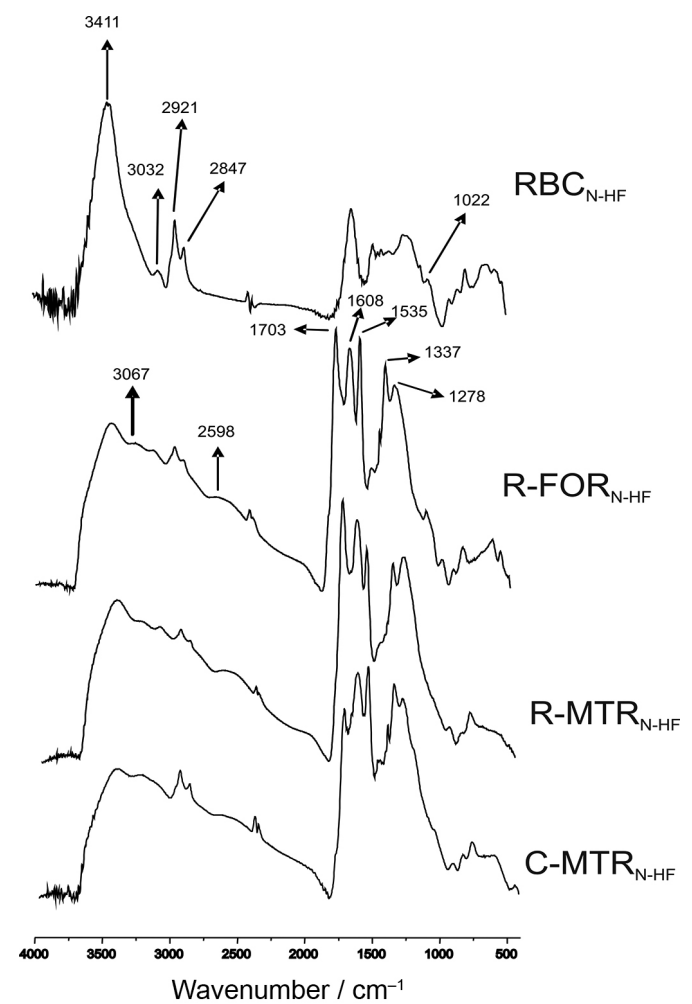

Figure 1. FTIR spectra of coal matrices C-MTR, R-MTR, R-FOR and RBC (a) before and (b) after treatment with $10 \%$ HF solution.

groups in the coal tailing after beneficiation of ROM coal is confirmed by the higher value of $\mathrm{I}_{1630} / \mathrm{I}_{2920}$ presented by R-MTR $\mathrm{HF}_{\mathrm{HF}}$ sample. R-FOR $\mathrm{HF}_{\mathrm{HF}}$ and $\mathrm{RBC}_{\mathrm{HF}}$ samples showed values of relative intensities and of $\mathrm{I}_{1630} / \mathrm{I}_{2920}$ similar to R-MTR $\mathrm{HF}_{\mathrm{HF}}$ (Table 2), suggesting a similar chemical composition among the studied tailings.

Thermal behavior of coal matrices treated with $10 \% \mathrm{HF}$ solution

Thermal decomposition behavior of the studied matrices treated with $10 \% \mathrm{HF}$ solution was relatively similar. The 
Table 2. Relative intensities (RI) and aromaticity index for the coal matrices C-MTR, R-MTR, R-FOR and RBC treated with $10 \%$ HF solution

\begin{tabular}{|c|c|c|c|c|c|c|c|c|c|}
\hline \multirow{2}{*}{ Sample } & \multicolumn{8}{|c|}{ Relative intensity / \% } & \multirow{2}{*}{$\begin{array}{c}\begin{array}{c}\text { Aromaticity } \\
\text { index }\end{array} \\
\mathrm{I}_{1630} / \mathrm{I}_{2920}\end{array}$} \\
\hline & $\mathrm{RI}_{3200}$ & $\mathrm{RI}_{2920}$ & $\mathrm{RI}_{1706}$ & $\mathrm{RI}_{1608}$ & $\mathrm{RI}_{1540}$ & $\mathrm{RI}_{1430}$ & $\mathrm{RI}_{1250}$ & $\mathrm{RI}_{1030}$ & \\
\hline C-MTR ${ }_{\mathrm{HF}}$ & 1.2 & 27.8 & n.d. & 34.6 & n.d. & 15.7 & 15.7 & 2.3 & 1.1 \\
\hline R-MTR ${ }_{\mathrm{HF}}$ & 2.5 & 13.7 & n.d. & 48.4 & n.d. & 9.4 & 21.3 & 3.4 & 2.0 \\
\hline $\mathrm{R}-\mathrm{FOR}_{\mathrm{HF}}$ & 2.5 & 13.5 & n.d. & 49.0 & n.d. & 9.5 & 21.9 & 3.0 & 2.2 \\
\hline $\mathrm{RBC}_{\mathrm{HF}}$ & 2.1 & 18.6 & n.d. & 42.3 & n.d. & 17.7 & 13.7 & 3.3 & 2.0 \\
\hline
\end{tabular}

n.d: not detected; HF: samples demineralized with $10 \%$ HF solution.

main temperature $(\mathrm{T})$ regions of decomposition are described as follows. For $\mathrm{T}<105^{\circ} \mathrm{C}$, the weight loss varied between 1.0 and $6.5 \%$ (data not shown), corresponding to the desorption of hydroscopic water from the organic matter. ${ }^{25}$ Mass loss in the temperature range 105 to $435^{\circ} \mathrm{C}$ $(\Delta \mathrm{m} 1)$ varied between 4.5 to $6.2 \%$, and was assigned to the decomposition of more thermolabile structures, such as alkyl and $O$-alkyl structures, phenolic and carboxylic groups..$^{25} \mathrm{In}$ the second $\mathrm{T}$ range, 435 to $535{ }^{\circ} \mathrm{C}(\Delta \mathrm{m} 2)$, the weight loss varied between 4.6 and $13.7 \%$ corresponding to less thermolabile structures, such as aromatic structures. In the third $\mathrm{T}$ range, $535-800{ }^{\circ} \mathrm{C}(\Delta \mathrm{m} 3)$, the weight loss may be assigned to higher thermostable structures, including condensed aromatic structures.

An additional thermogravimetric analysis was performed up to $1000{ }^{\circ} \mathrm{C}$. The weight loss in the region of 800 to $1000{ }^{\circ} \mathrm{C}(\Delta \mathrm{m} 4)$ (data not shown) corresponds to the decomposition aromatic structures more complex than those decomposed in $\Delta \mathrm{m} 3$ region.

The proportion of remaining mass for $\mathrm{T}>800{ }^{\circ} \mathrm{C}$ was $70-82 \%$ and for all samples, it was higher than the value obtained for the respective ash content (Table 1). Remaining mass for $\mathrm{T}>1000{ }^{\circ} \mathrm{C}$ ranged between 51 and $77 \%$ (Table 3) and it was also superior to the ash content. It is inferred therefore, that after being heated up to $1000{ }^{\circ} \mathrm{C}$, all samples still contained organic fraction in its structure. This extremely high thermal resistant fraction is probably composed of highly condensed structures that are typical for coal matrices. ${ }^{26}$

Thermogravimetric index [(TGI I), $(\Delta \mathrm{m} 3+\Delta \mathrm{m} 2) / \Delta \mathrm{m} 1],{ }^{22}$ is usually employed in the study of soil organic matter and it refers to the thermal lability of the organic fraction up to $\mathrm{T}=800{ }^{\circ} \mathrm{C}$. In this study, a second index was also calculated, TGI II $[(\Delta \mathrm{m} 4+\Delta \mathrm{m} 3+\Delta \mathrm{m} 2) / \Delta \mathrm{m} 1]$ which includes the decomposition up to $1000{ }^{\circ} \mathrm{C}$. TGI I ranged from 2.63 to 5.04 and the highest value was found for the sample R-MTR $\mathrm{HF}_{\mathrm{HF}}$ (Table 3). TGI II index was always superior to the TGI I and decreased in the same order as TGI I: $\mathrm{RMTR}_{\mathrm{HF}}>\mathrm{CMTR}_{\mathrm{HF}} \sim$ $\mathrm{RFOR}_{\mathrm{HF}}>\mathrm{RBC}_{\mathrm{HF}}$. According to our data, R-MTR contained a greater proportion of thermostable structures in the region 30 to $1000^{\circ} \mathrm{C}$ compared to the other samples. The proportion of highly thermostable organic structures $\left(\mathrm{T}>1000^{\circ} \mathrm{C}\right)$ can be estimated by the difference between the remaining mass at this temperature and the ash content. With exception of the R-FOR ${ }_{\mathrm{HF}}$ sample, to which this difference was 7\%, values ranged from 32 to $44 \%$ (data not shown). Therefore, it is inferred that samples C-MTR $\mathrm{HF}_{\mathrm{HF}}, \mathrm{R}-\mathrm{MTR}_{\mathrm{HF}}$ and $\mathrm{RBC}_{\mathrm{HF}}$ have around $33-44 \%$ of highly thermostable organic structures, and are therefore highly condensed. TGI I values obtained in this study are well above those usually observed for soil organic matter ${ }^{22}$ ( 0.30 to 1.50 ) and this fact is coherent with the presence of more complex and condensed structures in the coal matrices in comparison to soil samples. ${ }^{27,28}$

Table 3. Mass residue for $\mathrm{T}>800{ }^{\circ} \mathrm{C}$ and for $\mathrm{T}>1000{ }^{\circ} \mathrm{C}$, and thermogravimetric indexes (TGI I and TGI II) of the HF-treated coal matrices C-MTR, R-MTR, R-FOR and RBC, before and after $\mathrm{HNO}_{3}$ treatment

\begin{tabular}{lcccc}
\hline Sample & Residue $\left(\mathrm{T}>800{ }^{\circ} \mathrm{C}\right) / \%$ & Residue $\left(\mathrm{T}>1000{ }^{\circ} \mathrm{C}\right) / \%$ & TGI I & TGI II \\
\hline C-MTR $_{\mathrm{HF}}$ & 71 & 62 & 3.43 & 4.85 \\
R-MTR $_{\mathrm{HF}}$ & 62 & 51 & 5.04 & 7.16 \\
R-FOR $_{\mathrm{HF}}$ & 65 & 56 & 3.05 & 4.32 \\
RBC $_{\mathrm{HF}}$ & 83 & 78 & 2.63 & 3.71 \\
$\mathrm{C}_{-} \mathrm{MTR}_{\mathrm{N}-\mathrm{HF}}$ & 49 & 49 & 1.77 & 2.27 \\
R-MTR $_{\mathrm{N}-\mathrm{HF}}$ & 41 & 41 & 4.54 & 5.48 \\
R-FOR $_{\mathrm{N}-\mathrm{HF}}$ & 59 & 36 & 1.23 & 2.59 \\
RBC $_{\mathrm{N}-\mathrm{HF}}$ & 77 & 67 & 2.20 & 3.70 \\
\hline
\end{tabular}

HF: samples demineralized with $10 \% \mathrm{HF}$ solution; N-HF: samples treated with $\mathrm{HNO}_{3}$ and demineralized with $10 \% \mathrm{HF}$. 
Yield of $\mathrm{HNO}_{3}$ treatment and elemental composition of nitrated coal matrices

Nitration yield with $25 \% \mathrm{HNO}_{3}$ solution ranged between 67 and 92\% (Table 4). Two samples showed a decrease of $\mathrm{C}$ content after treatment $\left(\mathrm{C}-\mathrm{MTR}_{\mathrm{N}}\right.$ and R-MTR ${ }_{N}$ ) while in the samples R-FOR $R_{N}$ and $\mathrm{RBC}_{\mathrm{N}}$ no relevant change was observed (Tables 1 and 4). In all samples, an increase of $\mathrm{N}$ content occurred (Table 4) indicating the incorporation of $\mathrm{N}$ in the matrix structure. As a consequence, the $\mathrm{C} / \mathrm{N}$ ratio decreased to values that ranged from 11 to 20 (Table 4). The treatment with $10 \% \mathrm{HF}$ solution of the nitrated samples promoted an increase in the contents of $\mathrm{C}, \mathrm{H}$ and $\mathrm{N}$ (Table 4), as it was observed previously with the $\mathrm{HNO}_{3}$ untreated samples (Table 1).

$\mathrm{H} / \mathrm{C}$ ratio of the demineralized nitrated samples ranged from 0.46 to 0.55 (Table 4). This result does not indicate an increase of aromatic condensation after $\mathrm{HNO}_{3}$ treatment since this treatment does not promote this reaction. Considering that the concentration of $\mathrm{N}$ increased after the nitration, it is proposed that the inclusion of $\mathrm{N}$ in the structure occurs without the opening of the aromatic ring and thereby decreasing the $\mathrm{H} / \mathrm{C}$ ratio.

Changes in chemical composition of coal matrices after $25 \% \mathrm{HNO}_{3}$ treatment

FTIR spectra of the HF-treated samples after $\mathrm{HNO}_{3}$ treatment enabled the identification of the major changes promoted by the nitration (Figure 2). The main difference between spectra from Figures $1 \mathrm{~b}$ and 2 is the presence of carbonyl groups $\left(1700 \mathrm{~cm}^{-1}\right)$ and of the $\mathrm{C}-\mathrm{N}$ bonds $\left(1535 \mathrm{~cm}^{-1}\right)$ in the latter.

In comparison to the $\mathrm{HNO}_{3}$ untreated samples (Table 2), the nitrated matrices show higher values for $\mathrm{RI}_{1706}$ and $\mathrm{RI}_{1540}$
(Table 5) confirming the functionalization and nitration of the structure. Also, $\mathrm{I}_{1630} / \mathrm{I}_{2920}$ index increases after reaction with $\mathrm{HNO}_{3}$, although both values of $\mathrm{RI}_{2920}$ and $\mathrm{RI}_{1608}$ decrease after this treatment. These results confirm that both insertion of $\mathrm{N}$ and oxidation of sample occurred without breaking the aromatic ring.

The nitrated samples C-MTR $\mathrm{N}_{\mathrm{N}}$ and R-MTR $\mathrm{N}_{\mathrm{N}}$ showed higher values for $\mathrm{RI}_{3200}$ and $\mathrm{RI}_{3045}$, and lower value of $\mathrm{RI}_{2920}$ than the other two samples (Table 5). These results, along with the highest $\mathrm{I}_{1630} / \mathrm{I}_{2920}$ index, suggest greater aromatic condensation in the former, which is confirmed by the lower value of $\mathrm{H} / \mathrm{C}$ of $\mathrm{C}-\mathrm{MTR}_{\mathrm{N}-\mathrm{HF}}$ and $\mathrm{R}-\mathrm{MTR}_{\mathrm{N}-\mathrm{HF}}$ compared to $\mathrm{R}-\mathrm{FOR}_{\mathrm{N}-\mathrm{HF}}$ and $\mathrm{RBC}_{\mathrm{N}-\mathrm{HF}}$ samples.

$\mathrm{RBC}_{\mathrm{N}-\mathrm{HF}}$ sample showed the lowest value of $\mathrm{RI}_{1540}$ of the analyzed group indicating a low yield of $\mathrm{N}$ insertion in the structure, which is confirmed by the higher $\mathrm{C} / \mathrm{N}$ presented by this sample (Table 4) after nitration.

Comparing the values of relative intensities from Tables 2 and 5, it follows that the value of $\mathrm{RI}_{3200}$ decreases after nitration in all samples, indicating a decrease in the proportion of $-\mathrm{C}-\mathrm{H}$ groups of aromatics. This result supports the hypothesis that the insertion of $\mathrm{NO}_{2}$ occurred in the aromatic ring.

Thermal behavior of the samples treated with $25 \% \mathrm{HNO}_{3}$ solution

Weight loss for $\mathrm{T}<105{ }^{\circ} \mathrm{C}$ ranged between 1.7 to $7.9 \%$ (data not shown) indicating low humidity content in the samples. Thermal behavior of the nitrated samples differs from that of untreated samples in the temperature interval of $105-440{ }^{\circ} \mathrm{C}$, where two regions were identified: $105-220^{\circ} \mathrm{C}$ $(\Delta \mathrm{m} 1 \mathrm{I})$ and $220-440{ }^{\circ} \mathrm{C}(\Delta \mathrm{m} 1 \mathrm{II})$. The occurrence of these two regions can be associated with the insertion of functional groups and/or oxidation of the structure, which increase the thermolability.

Table 4. Yield of $\mathrm{HNO}_{3}$ treatment of the bulk sample, elemental composition, $\mathrm{C} / \mathrm{N}$ and $\mathrm{H} / \mathrm{C}$ ratios of coal matrices C-MTR, R-MTR, R-FOR and RBC before and after treatment with $10 \% \mathrm{HF}$

\begin{tabular}{|c|c|c|c|c|c|c|}
\hline Sample & Yield $^{a}$ & $\mathrm{C} / \%$ & $\mathrm{H} / \%$ & $\mathrm{~N} / \%$ & $\mathrm{C} / \mathrm{N}$ & $\mathrm{H} / \mathrm{C}$ \\
\hline C-MTR ${ }_{N}$ & $91.95 \pm 6.3^{b}$ & $37 \pm 0.4$ & $1.9 \pm 0.5$ & $2.6 \pm 0.2$ & $14 \pm 0.0$ & 0.61 \\
\hline R-MTR ${ }_{N}$ & $67.26 \pm 2.6$ & $12 \pm 1.2$ & $1.1 \pm 0.5$ & $0.9 \pm 0.1$ & $13 \pm 0.0$ & 1.10 \\
\hline R-FOR ${ }_{N}$ & $73.48 \pm 0.3$ & $8 \pm 2.1$ & $0.8 \pm 0.6$ & $0.7 \pm 0.3$ & $11 \pm 0.0$ & 1.20 \\
\hline $\mathrm{RBC}_{\mathrm{N}}$ & $91.66 \pm 0.4$ & $11 \pm 1.7$ & $0.5 \pm 0.2$ & $0.6 \pm 1.1$ & $20 \pm 4.0$ & 0.55 \\
\hline C-MTR $\mathrm{M}_{\mathrm{N}-\mathrm{HF}}$ & - & $65 \pm 1.0$ & $2.8 \pm 0.9$ & $4.6 \pm 1.0$ & $14 \pm 0.0$ & 0.52 \\
\hline R-MTR $\mathrm{M}_{\mathrm{N}-\mathrm{HF}}$ & - & $58 \pm 1.0$ & $2.2 \pm 0.2$ & $3.9 \pm 1.4$ & $16 \pm 0.0$ & 0.46 \\
\hline $\mathrm{R}-\mathrm{FOR}_{\mathrm{N}-\mathrm{HF}}$ & - & $55 \pm 5.0$ & $2.5 \pm 0.8$ & $4.0 \pm 1.5$ & $14 \pm 0.0$ & 0.55 \\
\hline $\mathrm{RBC}_{\mathrm{N}-\mathrm{HF}}$ & - & $57 \pm 8.0$ & $2.6 \pm 1.7$ & $1.2 \pm 1.0$ & $47 \pm 3.0$ & 0.55 \\
\hline
\end{tabular}

ayield of treatment with $25 \% \mathrm{HNO}_{3}$ solution; ${ }^{b}$ mean $(\mathrm{n}=2)$ (standard deviation); $\mathrm{N}$ : $\mathrm{HNO}_{3}$ treated samples; $\mathrm{N}-\mathrm{HF}$ : samples treated with $\mathrm{HNO}_{3}$ and demineralized with $10 \% \mathrm{HF}$. 


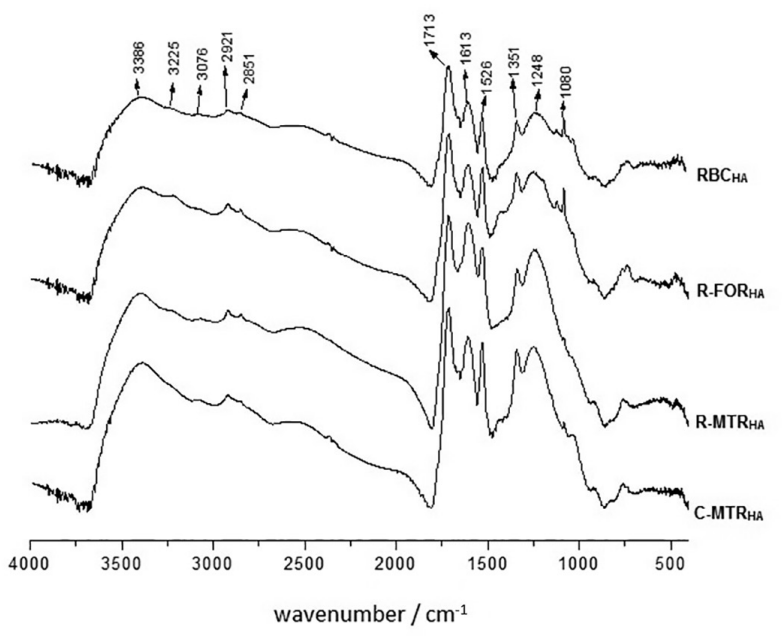

Figure 2. FTIR spectra of nitrated coal matrices C-MTR, R-MTR, R-FOR and $\mathrm{RBC}$ after $10 \% \mathrm{HF}$ treatment.

For the nitrated samples. TGI I values were lower than those in the $\mathrm{HNO}_{3}$ untreated samples (Table 3), confirming the increase of thermolability after treatment with nitric acid. This is further supported by TGI II values and consistent with the lower $\mathrm{C} / \mathrm{N}$ value (Table 4) after treatment with $25 \% \mathrm{HNO}_{3}$.

\section{Proposal for reactions occurring during treatment with $\mathrm{HNO}_{3}$ solution}

Concerning the chemical reactions that occurred during $25 \% \mathrm{HNO}_{3}$ treatment our results can be summarized as follow. After nitration, the $\mathrm{H} / \mathrm{C}$ ratio decreases or remains constant, indicating that there was no rupture of the aromatic ring during the process. The value of $\mathrm{RI}_{2920}$ related to the $\mathrm{C}-\mathrm{H}$ aliphatic bond decreased (Tables 2 and 5), indicating that the proportion of these functional groups also decreases. On the other hand, the relative intensity of the carbonyl, $\mathrm{RI}_{1706}$, increases indicating that an oxidation of structure occurred. Also the relative intensity of $\mathrm{C}-\mathrm{N}$ bond from $\mathrm{NO}_{2}$ group conjugated with the aromatic ring $\left(\mathrm{RI}_{1540}\right)$ increases and $\mathrm{RI}_{3200}$ decreases indicating the insertion of $\mathrm{N}$ in the aromatic structure. Thermostability of the samples decreases after treatment with $\mathrm{HNO}_{3}$ solution, and that can be associated with the functionalization of the structure. Therefore, our findings are in agreement with the mechanism proposed by Fong et al. ${ }^{11}$ In that mechanism, the presence of sulfuric acid is necessary as a reaction catalyzer. Our samples are pyrite $\left(\mathrm{FeS}_{2}\right)$ rich, ${ }^{1}$ which in turn, when in the presence of an oxidizing agent under heating, generates sulfuric acid, and thus acting as a catalyzer. ${ }^{2}$

Distribution of humic substances in coal matrices and characteristics of generated humic acid

Humic substances content $\left(\mathrm{C}_{\mathrm{HS}}\right)$ of the $\mathrm{HNO}_{3}$ untreated samples varied between 1.86 and $5.54 \mathrm{~g} \mathrm{~kg}^{-1}$ accounting for 0.5 to $4.2 \%$ of the total carbon present in the sample (Table 6). These results are consistent with carbonaceous matrices where carbon is predominantly in the reduced form. ${ }^{29}$ In these samples, the $\mathrm{C}_{\mathrm{HA}}$ levels were relatively low and did not exceed the value of $2.8 \mathrm{~g} \mathrm{~kg}^{-1}$.

The coal tailing R-MTR showed higher levels of $\mathrm{C}_{\mathrm{HS}}$ and a greater value for $\mathrm{C}_{\mathrm{HS}} / \mathrm{C}_{\mathrm{T}}$ than the respective ROM coal. It seems that the coal tailing resulting from the beneficiation process is a more oxidized fraction, in spite of its greater proportion of inorganic fraction in comparison to the ROM coal. This enrichment is mainly in the HA fraction, as the ratio $\mathrm{C}_{\mathrm{HA}} / \mathrm{C}_{\mathrm{HS}}$ is greater in the three samples of coal tailings compared to the ROM coal (Table 6).

$\mathrm{C}_{\mathrm{HS}}$ content increased after the nitration in all samples and ranged from 19 to $34.6 \mathrm{~g} \mathrm{~kg}^{-1}$ (Table 6). $\mathrm{C}_{\mathrm{HS}} / \mathrm{C}_{\mathrm{T}}$ ratio consequently increased, ranging between 7.6 and $31 \%$. Although, showing the greatest HS enrichment after nitration, C-MTR sample showed the smallest $\mathrm{C}_{\mathrm{HS}} / \mathrm{C}_{\mathrm{T}}$ ratio, indicating greater resistance in generating humic substances after the reaction with $\mathrm{HNO}_{3}$. Increase in the HS content after treatment with $\mathrm{HNO}_{3}$ was observed in both FA and HA fractions. However, the HA enrichment was more pronounced in the HA fraction. The proportion $\mathrm{C}_{\mathrm{HA}} / \mathrm{C}_{\mathrm{HS}}$ ranged from 5 to $48 \%$ in the original carbonaceous samples, and after reaction with $\mathrm{HNO}_{3}$ these values passed to values ranging from 62 to $84 \%$ (Table 6).

Table 5. Relative intensities (RI) and aromaticity index of coal matrices C-MTR $\mathrm{N}_{\mathrm{HF}}, \mathrm{R}-\mathrm{MTR}_{\mathrm{N}-\mathrm{HF}}, \mathrm{R}-\mathrm{FOR}_{\mathrm{N}-\mathrm{HF}}$ and $\mathrm{RBC}_{\mathrm{N}-\mathrm{HF}}$

\begin{tabular}{|c|c|c|c|c|c|c|c|c|c|c|c|}
\hline \multirow{2}{*}{ Sample } & \multicolumn{10}{|c|}{ Relative intensity / \% } & \multirow{2}{*}{$\begin{array}{c}\text { Aromaticity } \\
\text { index }\end{array}$} \\
\hline & $\mathrm{RI}_{3200}$ & $\mathrm{RI}_{3030}$ & $\mathrm{RI}_{2920}$ & $\mathrm{RI}_{1706}$ & $\mathrm{RI}_{1608}$ & $\mathrm{RI}_{1540}$ & $\mathrm{RI}_{1430}$ & $\mathrm{RI}_{1330}$ & $\mathrm{RI}_{1250}$ & $\mathrm{RI}_{1030}$ & \\
\hline C-MTR $\mathrm{N}-\mathrm{HF}_{\mathrm{F}}$ & 1.1 & 1.1 & 4.1 & 19.6 & 20.3 & 18.1 & 3.7 & 16.5 & 16.4 & n.d. & 4.9 \\
\hline $\mathrm{R}-\mathrm{MTR}_{\mathrm{N}-\mathrm{HF}}$ & 0.4 & 0.8 & 2.2 & 28.6 & 20.5 & 16.7 & n.d. & 14.3 & 16.5 & n.d. & 9.4 \\
\hline R-FOR ${ }_{\mathrm{N}-\mathrm{HF}}$ & n.d. & n.d. & 5.7 & 23.1 & 17.7 & 17.1 & 2.3 & 16.2 & 12.5 & 5.4 & 3.1 \\
\hline $\mathrm{RBC}_{\mathrm{N}-\mathrm{HF}}$ & n.d. & n.d. & 17.7 & 11.8 & 22.0 & 8.2 & 10.6 & n.d. & 16.5 & 11.4 & 1.2 \\
\hline
\end{tabular}

n.d.: not detected. 
Table 6. Content of $\mathrm{C}$ allocated in humic substances $\left(\mathrm{C}_{\mathrm{HS}}\right)$, in fulvic acids $\left(\mathrm{C}_{\mathrm{FA}}\right)$ and humic acids $\left(\mathrm{C}_{\mathrm{HA}}\right)$, proportion of $\mathrm{C}_{\mathrm{HS}}$ compared to $\mathrm{C}$ of the total sample $\left(\mathrm{C}_{\mathrm{HS}} / \mathrm{C}_{\mathrm{T}}\right)$ and proportion of $\mathrm{C}_{\mathrm{HA}}$ of $\mathrm{HS}\left(\mathrm{C}_{\mathrm{HA}} / \mathrm{C}_{\mathrm{HS}}\right)$ in the $\mathrm{HNO}_{3}$ untreated and nitrated coal matrices C-MTR, R-MTR, R-FOR and RBC

\begin{tabular}{|c|c|c|c|c|c|}
\hline Sample & $\mathrm{C}_{\mathrm{HS}} /\left(\mathrm{g} \mathrm{kg}^{-1}\right)$ & $\mathrm{C}_{\mathrm{FA}} /\left(\mathrm{g} \mathrm{kg}^{-1}\right)$ & $\mathrm{C}_{\mathrm{HA}} /\left(\mathrm{g} \mathrm{kg}^{-1}\right)$ & $\mathrm{C}_{\mathrm{HS}} / \mathrm{C}_{\mathrm{T}}$ & $\mathrm{C}_{\mathrm{HA}} / \mathrm{C}_{\mathrm{HS}}$ \\
\hline C-MTR ${ }^{b}$ & $1.86 \pm 0.05^{\mathrm{a}}$ & $1.76 \pm 0.11$ & 0.10 & 0.45 & 5.4 \\
\hline C-MTR ${ }_{N}$ & $27.92 \pm 0.99$ & $0.67 \pm 1.03$ & 17.25 & 7.6 & 61.8 \\
\hline R-MTR ${ }^{b}$ & $5.54 \pm 0.70$ & $2.70 \pm 0.60$ & 2.84 & 3.4 & 48.7 \\
\hline R-MTR ${ }_{N}$ & $19.07 \pm 0.96$ & $3.64 \pm 0.44$ & 15.42 & 15.7 & 80.9 \\
\hline R-FOR ${ }^{b}$ & $2.63 \pm 0.41$ & $2.40 \pm 0.2$ & 0.23 & 3.9 & 8.7 \\
\hline $\mathrm{R}-\mathrm{FOR}_{\mathrm{N}}$ & $22.51 \pm 0.61$ & $3.69 \pm 0.25$ & 18.81 & 28.2 & 83.6 \\
\hline $\mathrm{RBC}^{\mathrm{b}}$ & $4.89 \pm 1.71$ & $3.18 \pm 0.18$ & 1.71 & 4.2 & 35.0 \\
\hline $\mathrm{RBC}_{\mathrm{N}}$ & $34.59 \pm 1.25$ & $14.18 \pm 5.4$ & 20.40 & 30.6 & 59.5 \\
\hline
\end{tabular}

${ }^{\mathrm{a}}$ Mean $(\mathrm{n}=2) \pm$ standard deviation; ${ }^{\mathrm{b}} \mathrm{HNO}_{3}$ untreated; $\mathrm{N}$ : $\mathrm{HNO}_{3}$ treated.

Contents of $\mathrm{C}$ and $\mathrm{N}$ of the extracted $\mathrm{HA}$ after nitration were similar between samples, and ranged between 54.0 and $58.4 \%$ and 3.7 and $3.9 \%$, respectively (Table 7). The C/N ratio ranged between 14 and 16 . These values are consistent with the values usually observed for HA in soil. ${ }^{30,31}$

The FTIR spectra of HA extracted from the nitrated matrices showed, in general, the same pattern as the spectra of the nitrated coal samples (Figure 3). The main differences were: a shift of the band of $\mathrm{C}=\mathrm{O}$ stretching from 1703 to $1713 \mathrm{~cm}^{-1}$ and of the band of $\mathrm{C}=\mathrm{C}$ stretching from 1603 to $1613 \mathrm{~cm}^{-1}$. These shifts to higher wavenumbers suggest the occurrence of less condensed functionalized aromatics group in the HA in comparison to the nitrated coal matrices. The presence of the band in $1526 \mathrm{~cm}^{-1}$ shows that during treatment with $25 \% \mathrm{HNO}_{3}$ solution, the incorporation of $\mathrm{NO}_{2}$ in the coal structure occurred in the HA fraction as already seen in other coals from Southern Brazil. ${ }^{31,32}$

Table 7. Elemental composition of humic acids (HA) extracted from nitrated coal matrices C-MTR, R-MTR, R-FOR and RBC

\begin{tabular}{lccc}
\hline Sample & C / \% & N / \% & C/N \\
\hline C-MTR $_{N}$ & 56.8 & 3.94 & 14 \\
R-MTR $_{N}$ & 58.4 & 3.72 & 16 \\
R-FOR $_{N}$ & 54.0 & 3.92 & 14 \\
RBC $_{N}$ & 54.1 & 3.71 & 15 \\
\hline
\end{tabular}

The values of relative intensities of HA were, in general, similar between samples R-FOR and RBC (Table 8), indicating that after treatment with $\mathrm{HNO}_{3}$ solution the $\mathrm{HA}$ of these samples showed a similar chemical composition. These results corroborate the $\mathrm{C} / \mathrm{N}$ data (Table 7). HA C-MTR $\mathrm{N}_{\mathrm{N}}$ showed lower values for $\mathrm{RI}_{1713}$ and $\mathrm{RI}_{1610}$ and greater value of $\mathrm{RI}_{1526}$ than those of the HA R-MTR sample (Table 8). These findings together with the $\mathrm{C} / \mathrm{N}$ values indicate that $\mathrm{HA}$ of coal tailing, which has a higher proportion of aromatic groups, was more susceptible to oxidation, but incorporated less $\mathrm{N}$ than the HA of respective ROM coal. Additionally, the ratio $\mathrm{I}_{1630} / \mathrm{I}_{2920}$ was higher for HA R-MTR sample, following the same behavior observed for the organic fraction of the nitrated carbonaceous matrices (Table 5). The aromaticity index of $\mathrm{HA}\left(\mathrm{I}_{1630} / \mathrm{I}_{2920}\right)$ ranged from 6.5 to 15 and is greater than the aromaticity index usually observed for soil HA. ${ }^{31}$

\section{Conclusion}

Nitration of the coal matrices resulted in an increase in nitrogen content, and promoted the oxidation of the coal structure, leading to its functionalization. Nitrogen insertion occurred mainly in the aromatic rings.

Treating carbonaceous matrices with $25 \% \mathrm{HNO}_{3}$ solution under reflux for generating humic substances was satisfactory since it increased the proportion of extractable HS from 3 to 9 times.

Increase in the humic substances content after treatment with $\mathrm{HNO}_{3}$ was found mostly in the fraction of humic acids (62 to $84 \%$ ), into whose structure the nitro group was inserted. The generated humic acids showed, in general, similar chemical composition to HA of soils, but a greater degree of aromaticity.

Based on the higher yields obtained with the coal tailings, it is inferred that these residues, when nitrated, may represent a promising source for humic substances. The use of nitrated coal tailings as a soil fertilizer or conditioner should though be further investigated by bioassays.

\section{Acknowledgments}

The authors thank CNPq and FAPERJ for financial support and to Prof Ivo André Homrich Schneider (Engineering School, UFRGS) for the coal matrices supply. 


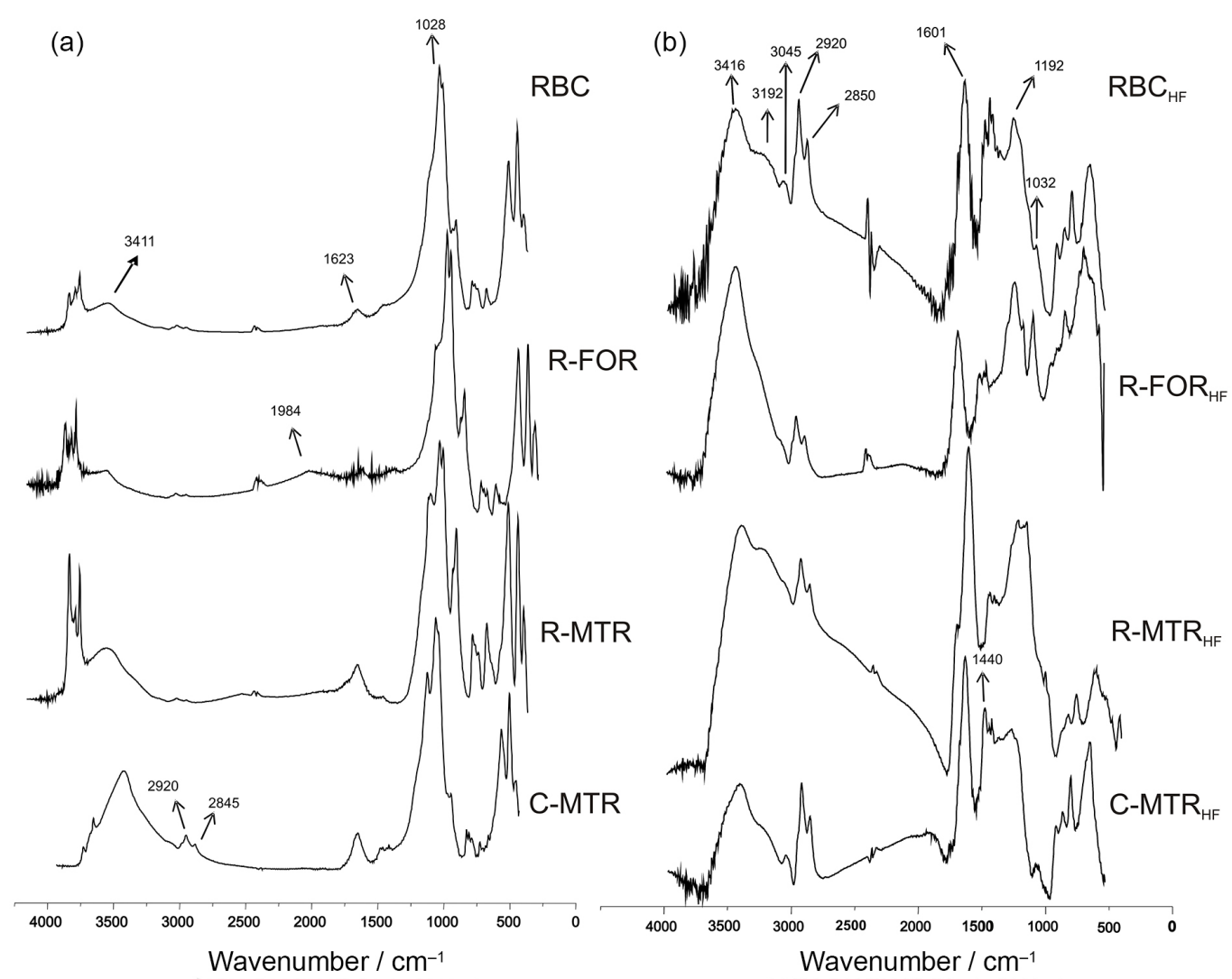

Figure 3. FTIR spectra of HA extracted from the nitrated coal matrices C-MTR, R-MTR, R-FOR and RBC.

Table 8. Relative intensities and aromaticity index of HA in the nitrated coal matrices C-MTR, R-MTR, R-FOR and RBC

\begin{tabular}{|c|c|c|c|c|c|c|c|c|c|}
\hline \multirow{2}{*}{ Sample } & \multicolumn{8}{|c|}{ Relative intensity / \% } & \multirow{2}{*}{$\begin{array}{c}\text { Aromaticity } \\
\text { index }\end{array}$} \\
\hline & $\mathrm{RI}_{3070}$ & $\mathrm{RI}_{2929}$ & $\mathrm{RI}_{1713}$ & $\mathrm{RI}_{1610}$ & $\mathrm{RI}_{1526}$ & $\mathrm{RI}_{1338}$ & $\mathrm{RI}_{1248}$ & $\mathrm{RI}_{1080}$ & \\
\hline HA C-MTR $_{N}$ & 0.7 & 2.1 & 29 & 21 & 18 & 13 & 13 & n.d & 10 \\
\hline HA R-MTR $_{\mathrm{N}}$ & 0.8 & 1.6 & 32 & 24 & 16 & 10 & 14 & n.d & 15 \\
\hline HA R-FOR ${ }_{N}$ & 0.8 & 3.1 & 33 & 20 & 15 & 11 & 11 & 3.9 & 6.5 \\
\hline HA RBC ${ }_{N}$ & 0.7 & 2.8 & 30 & 20 & 16 & 12 & 11 & 5.0 & 9.3 \\
\hline
\end{tabular}

\section{References}

1. Kalkkreuth, W.; Holz, M.; Kern, M.; Machado, G.; Mexias, A.; Silva, M. B.; Willett, J.; Finkelman, R.; Burger, H.; Int. J. Coal Geol. 2006, 68, 79 .

2. Campos, M. L.; Almeida, J. A.; Silveira, C. B.; Gatiboni, L. C.; Albuquerque, J. A.; Mafra, A. L.; Miquelluti, D. J.; Filho, O. K.; Santos, J. C. P.; Rev. Ciênc. Agrovet. 2010, 9, 198.

3. Machado, L. A.; Schneider, I. A. H.; Rev. Esc. Minas (Ouro Preto, Braz.) 2008, 61, 329.

4. Clasen, H. A. C.; Lessa, R. T.; Kaemmerer, M.; Koetz, P. R.; Rev. Bras. Agro. 1998, 1, 35.

5. Canellas, L. P.; Santos, G. A.; Moraes, A. A.; Rumjanek, V. M.; Olivares, F. L.; Rev. Bras. Cienc. Solo 2000, 24, 741.

6. Passos, R. R.; Ruiz, H. A.; Mendonça, E. S.; Cantarutti, R. B.;
Souza, A. P.; Rev. Bras. Cienc. Solo 2007, 31, 1119.

7. Smith, R. C.; Howard, H. C.; J. Agric. Food Chem. 1935, 57, 512.

8. Fuchs, W.; Polansky, T. S.; Sandhoff, A. G.; Ind. Eng. Chem. Res. 1943, 35 .

9. Angelo, L. C.; Mangrich, A. S.; Montovani, K. M.; Santos, S. S; J. Soils Sediments 2014, 14, 353.

10. Linhares, C. R.; Lemke, J.; Auccaise, R.; Duó, D. A.; Ziolli, R. L.; Kwalpinski, W.; Novotny, E. H.; Pesq. Agropec. Bras. 2012, 47, 693.

11. Fong, S. S.; Seng, L.; Majri, N. B.; Mat, H. B.; J. Braz. Chem. Soc. 2007, 18, 34.

12. Araujo, J. R.; Archanjo, B. S.; Souza, K. R.; Kwalpinski, W.; Falcão, N. P. S.; Novotny, E. H.; Achete, C. A.; Biol. Fertil Soils 2014, 50, 1223. 
13. Gonçalves, C. N.; Dalmolin, R. S. D.; Dick, D. P.; Knicker, H.; Klamt, E.; Koegel-Knabner, I.; Geoderma 2003, 116, 373.

14. Rumpel, C.; Rabia, N.; Derenne, S.; Quenea, K.; Eusterhues, K.; Kögel-Knabner, I.; Mariotti, A.; Org. Geochem. 2006, 37, 1437.

15. Trompowsky, P. M.; Benites, V. M.; Madari, B. E.; Pimenta, A. S.; Hockaday, W. C.; Hatcher, P. G.; Org. Geochem. 2005, 36, 1480.

16. Fong, S. S.; Seng, L.; Mat, H. B.; J. Braz. Chem. Soc. 2007, 18, 41.

17. Milani, E. J.; Melo, J. H. G.; Souza, P. A.; Fernandes, L. A.; França, A. B.; Bol. Geoc. Petrobras 2007, 15, 265.

18. Tan, K. H.; Humic Matter in Soil and the Environment: Principles and Controversies; Marcel Dekker: New York, USA, 2003.

19. Farmer, V. C.; Infrared Spectra of Minerals; Mineralogical Society: London, UK, 1974.

20. Chefetz, B.; Hatcher, P.; Hadar, Y.; Chen, Y.; J. Environ. Qual. 1996, 25, 776 .

21. Gerzabek, M. H.; Antil, R. S.; Kögel-Knabner, I.; Knicker, H.; Kirchmann, H.; Haberhauer, G.; Eur. J. Soil Sci. 2006, 57, 485.

22. Benites, V. M.; Mendonça, E. S.; Schaeffer, C. E. G. R.; Novotny, E. H.; Reis, E. L.; Ker, J. C.; Geoderma 2005, 127, 104.

23. Swift, R. S. In Methods of Soil Analysis Part 3-Chemical Methods; Spark D. L., ed.; SSSA and ASA: Madison, WI, 1996, p. 1001.
24. Dick, D. P.; Gomes, J.; Rosinha, P. B.; Rev. Bras. Cienc. Solo 1998, 22, 603.

25. Critter, S. A. M.; Airoldi, C.; J. Braz. Chem. Soc. 2006, 17, 1250.

26. Silva, I. R.; Mendonça, E. S. In Fertilidade do Solo; Novais, R. F.; Alvarez, V. H.; Barros, N. F.; Fontes, R. L. F.; Cantarutti, R. B.; Neves, J. C. L., eds.; SBCS: Viçosa, 2007, p. 275.

27. Speight, J. G.; Mineral Matter, Handbook of Coal Analysis; John Wiley \& Sons: New Jersey, USA, 2005.

28. White, C. M.; Smith, D. H.; Jones, K. L.; Goodman, A. L.; Jikich, S. A.; LaCount, R. B.; DuBose, S. B.; Ozdemir, E.; Morsi, B. I.; Schroeder, K. T.; Energy Fuels 2005, 19, 659.

29. Miranda, C. C.; Canellas, L. P.; Nascimento, M. T.; Rev. Bras. Cienc. Solo 2007, 31, 905.

30. Schiavo, J. A.; Busato, J. G.; Martins, M. A.; Canellas, L. P.; Sci. Agric. 2009, 66, 353.

31. Dick, D. P.; Mangrich, A. S.; Menezes, S. M. C.; Pereira, B. F.; J. Braz. Chem. Soc. 2002, 13, 177.

32. Dias, B. O.; Silva, C. A.; Soares, E. M. B.; Bettiol, W.; Guerreiro, M. C.; Belizário, M. H.; Rev. Bras. Cienc. Solo. 2009, 33, 885.

Submitted: November 20, 2015

Published online: August 9, 2016

FAPERGS/CAPES has sponsored the publication of this article. 